a function of the brain, this hypothesis is directly opposed to the law of the specific energy of the senses. This law has been much discussed and is not universally accepted, but since Dr. EdridgeGreen cites it with approval "(Physiology of Vision," p. 1) the argument should have some weight with him.

Probably most competent judges will agree that the light stimulus is of a photo-chemical nature and that the physical basis is one of molecular forced vibrations. They will, however, suspend judgment as to the exact details of the mechanism.

(To be continued).

\title{
ANNOTATIONS
}

\section{Compulsory training and examination in Ophthalmology}

During the past two years the General Medical Council has been urged to compel all medical students to study ophthalmology and to have them examined by specialists before they receive a licence to practise. Ophthalmic surgeons are so convinced of the necessity of this measure that the Oxford Ophthalmological Congress, the Council of British Ophthalmologists, and the Ophthalmological Society of the United Kingdom passed unanimous resolutions which have been considered by the General Medical Council. At the recent Congress of the Ophthalmological Society, the President, Mr. J. B. Story, P.R.C.S.I., devoted his opening address entirely to this question. He regretted that the General Medical Council had refused to institute a formal examination in diseases of the eye and had only consented to ask for some evidence of practical training in the subject. He pointed out that it was essential for every medical practitioner to possess a working knowledge of ophthalmology, and for two reasons: because rarely can a qualified man escape the necessity of treating eye patients at some time in his career, and secondly, the evidence afforded by an examination of the eye is needed for the diagnosis of many ordinary medical diseases; in fact, it has been stated that the ophthalmoscope is as essential as the stethoscope.

The General Medical Council had, he said, come to no logical conclusion, and had virtually tried to shift the responsibility on to the Hospital Medical Schools, who are empowered to refuse certificates to students who do not acquire a sufficient knowledge of eye diseases. The President reminded the Society that all the Irish licensing bodies had held a special clinical examination, and that this fact disposed of the objection that there was no time for 
the student to learn the subject. He emphasized the value of an actual clinical test, for after thirty years' experience as an examiner, he knew how often candidates were well versed in book knowledge, but unable to diagnose the simplest ocular abnormality.

He said that the General Medical Council should be urged to institute the following reforms:

1. That each candidate for a licence to practise be compelled to attend an ophthalmic clinic for three months.

2. That the final examination shall include a clinical examination by ophthalmic surgeons.

\section{A new Diploma in Ophthalmic Medicine and Surgery}

A forward step has been taken by the London Conjoint Board in instituting a diploma in ophthalmic medicine and surgery (D.O.M.S., R.C.P. \& S. Eng.). Candidates may enter for Part I of the examination, which includes the anatomy and embryology of the visual apparatus, the physiology of vision, and elementary optics, at any time after a registrable qualification has been obtained in medicine, surgery, and midwifery. Part II, upon optical defects of the eye, ophthalmic medicine and surgery, and pathology, may be taken on the completion of one year of special study of ophthalmology, and the production of certain certificates. The institution of this diploma amply justifies the efforts of those who have advocated the adequate study of ophthalmology and furnishes the best answer to the attitude of the General Medical Council towards the matter. We congratulate the Royal Colleges upon their enlightened action.

\section{Artificial Daylight}

The problem of artificial daylight is one of considerable importance in many industries. One of the recent attempts at solving the problem consists in the use of carefully combined colour reflectors in contrast to the earlier methods in which transmission through tinted screens was employed. The apparatus is known as the Sheringham daylight and is the result of the combined work of a physicist, Mr. L. C. Martin, an artist, Mr. G. Sheringham, and an expert on camouflage problems, Major Klein. Mr. Martin read a paper on the light before the Illuminating Engineering Society. The paper and the subsequent interesting discussion are fully reported in the Illuminating Engineer for February, 1920. One very interesting point was the difficulty of defining daylight on account of its great variability. In an editorial in the same journal the editor writes: "In order that the whole subject may 